\title{
The outcomes of external dacryocystorhinostomy with bi- canalicular silicone knot started in the lacrimal sac without suturing posterior flap
}

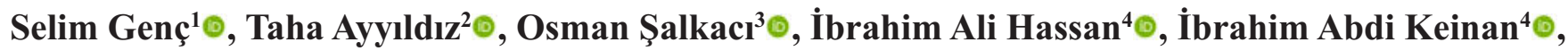 \\ Hanefi Çakır ${ }^{5} \odot$
}

${ }^{1}$ Department of Ophthalmology, University of Health Sciences, Beyoğlu Reşat Berger Training and Research Hospital, Istanbul, Turkey ${ }^{2}$ Department of Ophthalmology, Bursa City Hospital, Bursa, Turkey

${ }^{3}$ Department of Ophthalmology, Kartal Lütfi Kırdar Training and Research Hospital, Istanbul, Turkey

${ }^{4}$ Department of Ophthalmology, University of Health Sciences, Somalia Mogadishu Turkey Recep Tayyip Erdoğan Training and

Research Hospital, Mogadishu, Somalia

${ }^{5}$ Department of Ophthalmology, Türkiye Hospital, İstanbul, Turkey

\begin{abstract}
Objectives: During external dacryocystorhinostomy (DSR) - Bicanalicular silicone tube implantation (BSTI), it is aimed to utilize the mechanical pressure effect due to the initiation of silicone knotting inside the lacrimal sac and evaluate the effectiveness of this modified technique in which the sac and nasal mucosa posterior flaps are not sutured.

Methods: Sixty-six patients between the ages of 8-57 years who were admitted to Kartal Lütfi Kirdar Training and Research Hospital and Somalia Mogadishu Recep Tayyip Erdogan Training and Research Hospital Eye Diseases outpatient clinic with irrigation and lacrimal secretion complaints between January 1, 2010 and December 31, 2019 were included in the study. In these patients with lacrimal stenosis, external dacryocystorhinostomy (DSR) and Bicanalicular silicone tube implantation surgery method were applied.

Results: A total of 66 patients, 3 males (4.5\%) and 63 females (95.5\%), were included in this study. The mean age of the patients was $45(8-57)$ years. It was determined that 4 of the patients who were followed up for an average of 16 months developed atrophic mucosa due to chronic rhinitis, and 6 developed nasolacrimal ductus obstruction due to excessive wound healing due to young age.

Conclusions: When the comfort and complications it provides are evaluated together, this technique emerges as a preferred method.

Keywords: External dacryocystorhinostomy, bicanalicular silicone knot, posterior flap
\end{abstract}

T The tear drainage system covers the part between the punctums and the place where the nasolacrimal canal opens to the nose. Tears flow into the nasal mucosa thanks to the lacrimal pump system. Any blockage at any point in this system will prevent tear flow, and tears will accumulate in the conjunctiva and reveal a condition called epiphora.

The surgical intervention to be performed according to the location of the obstruction varies, and the surgical methods related to the tear drainage system 
are as follows: (1) Dacryocystorhinostomy, (2) Dacryocystorhinostomy + bicanalicular silicone tube (DSR + BST), (3) Canaliculodacryocystorhinostomy, (4) Conjunctivodacryocystorhinostomy, (5) Conjunctivorinostomy, and (6) Conjunctivodacryocystotomy. While the first two methods to be preferred in nasolacrimal sac and nasolacrimal canal obstructions are "bicanalicular silicone tube implantation with dacryocystorhinostomy", one of the other methods can be applied in case of a blockage in the canals extending from the punctal to the sac. The most preferred methods are Conjunctivodacryocystorhinostomy (CDSR) and Conjunctivorinostomy (CR). These two methods provide the flow of tears by creating a passage from the conjunctiva directly to the nasal cavity with the help of silicone and Peyrex tubes.

Failure to open the bone and/or mucosa window sufficiently and the closure of the osteotomy site in endonasal DCR surgeries are seen as an important problem [1-3], and in this respect, External DCR remains a successful and reliable method in nasolacrimal canal occlusion compared to other techniques. High success has been reported in many published case series $[4,5]$. However, it can be considered as a medium-length and difficult surgery. The most difficult and time consuming stage for surgeons is the stage in which flaps are formed and sutured. At the same time, the excessive bleeding that develops during the preparation of the nasal mucosa flaps makes the operation area difficult to see. Some variations have been introduced to this stage in order to shorten the operation time and reduce bleeding, and the use of only anterior flaps has been a frequently tried method [6-9].
In our study, it is aimed to benefit from the mechanical compression effect due to the initiation of silicone knotting in the tear sac during Bicanalicular silicone tube implantation (BSTI) and to evaluate the effectiveness of external dacryocystorhinostomy (DCR) operation in which the sac and nasal mucosa posterior flaps are not sutured.

\section{METHODS}

Sixty-six patients between the ages of 8-57 who presented with the complaints of irrigation and lacrimal secretion to the Kartal Lütfi Kırdar Training and Research Hospital Research Hospital and Somalia Mogadishu Recep Tayyip Erdoğan Training and Research Hospital ophthalmology outpatient clinic between January 1, 2010 and December 31, 2019 were included in the study. Ethics committee approval was obtained for our study (20.02.1019/5549-614).

\section{Surgical Technique}

After the eye area was wiped with Baticon, local infiltrative anesthesia was performed. A tampon impregnated with Pantocaine and Adrenaline was placed through the nose half an hour before the operation to reduce bleeding. Lacrimal, nasociliary and infraorbital local anesthesia was applied with jetocaine (Lidocaine HCL). The tear sac and nasal mucosa were exposed as in classical DCR (Fig. 1a and 1b). The bone window was opened to be $1 \times 1.5 \mathrm{~cm}$. Hshaped incisions were modified so that the posterior flap in the tear sac and the anterior flap in the nasal mucosa were quite long. After the BSTI was

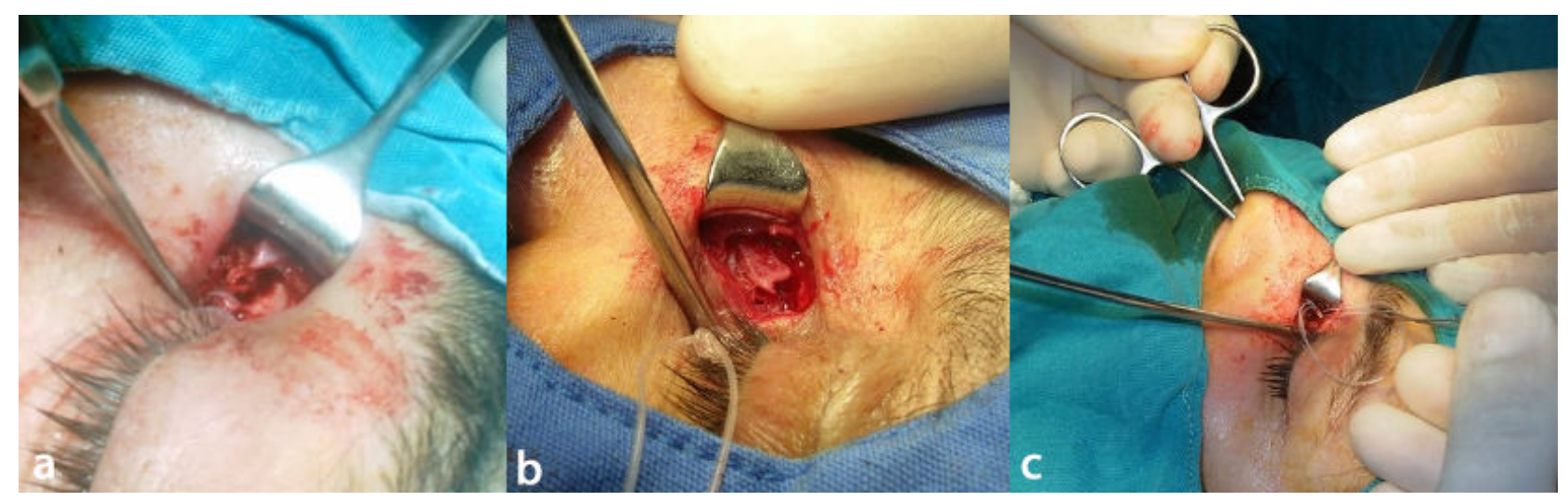

Fig. 1. Surgical stages. (a) lacrimal sac and nose exposure, (b) lacrimal sac and nasal mucosa suturing, and (c) taking silicone into the nose. 
performed, the ends of the bicanalicular silicone tube were knotted 10-15 times starting from the pouch and extended into the nose. The tear sac and nasal mucosa anterior flaps were sutured with 6/0 Vicryl (Fig. 1b and 1c). After the deep tissues and skin were covered, bleeding was controlled and systemic antibiotics, antiinflammatory, analgesic, topical antibiotics and steroid eye drops were recommended for 10 days after surgery. The patients were reminded to avoid excessive straining and blowing for at least 2 weeks, and they were asked to come to the control examinations on the postoperative $1^{\text {st }}$ day, 1 st week, $1^{\text {st }}, 6^{\text {th }}$ and $12^{\text {th }}$ months and then once a year. Antibiotic lavage was applied when exudate was detected around the tube in the samples of the cases. The case records were reviewed retrospectively.

\section{Statistical Analysis}

Continuous variables were shown as average \pm standard deviation, while categorical variables were expressed as frequency and percentage.

\section{RESULTS}

A total of 66 patients, 3 males (4.5\%), 63 females (95.5\%) were included in this study. The mean age of the patients was 45 years (8-57 years) and the mean follow-up period was 16 (4-48) months. Silicone tubes were removed at an average of 7 months. Follow-up examinations were performed on the $1^{\text {st }}$ day, $1^{\text {st }}$ week, $1^{\text {st }}, 6^{\text {th }}$ and $12^{\text {th }}$ months following the surgery and once a year. According to the last examination findings of

\section{Table 1. Clinical and demographic findings of the cases}

\begin{tabular}{lc}
\hline Findings & Data \\
\hline Gender, $\mathrm{n}(\%)$ & \\
\multicolumn{1}{c}{ Female } & $63(95.5)$ \\
Male & $3(4.5)$ \\
Mean age (years) (range) & $45(8-57)$ \\
Follow up time (months) (range) & $16(4-48)$ \\
Operation failure rate, $\mathrm{n}(\%)$ & $10(15.1)$ \\
Atrophic mucosa $(\mathrm{n}=4)$ & \\
Excessive wound healing $(\mathrm{n}=6)$ & \\
\hline
\end{tabular}

the patients, the passage was found to be obstructed in $10(15.1 \%)$ patients. While failure was due to nasal mucosa disorder in 4 patients; In 6 patients, it was found that it developed due to nasolacrimal obstruction due to excessive wound healing (Table 1).

\section{DISCUSSION}

BSTI is an application that increases the success rates in external DCR surgeries. Suturing the posterior flaps is a very difficult and time-consuming procedure. In this study, the technique of flap incision was changed, leaving the lacrimal sac posterior flap long, and the silicon tubes knotted were pushed towards the nasal mucosa by mechanical effect. In addition, the long anterior flap of the nasal mucosa was sutured with the anterior wall of the lacrimal sac to create a wide space towards the nose. With this method, it was planned to shorten the operation time and increase the success rate of the operation. In our study, only the anterior flaps were sutured and the posterior flaps were left without suturing.

Suturing the posterior flaps is an uncommon method in terms of difficulty of application and prolonging the duration of the surgery. According to previous studies on this subject, the variations that can be applied to flaps can be grouped under four main headings: 1) creation of only anterior flap, 2) creation of anterior flap and excision of the posterior flap, 3) creation of anterior and posterior flap, and 4) No flap creation [8]. Also, there are three procedures that can be performed for the posterior flap during external DCR: 1. Excision, 2. Leaving without intervention, and 3. Shaping and suturing directly to the nasal mucosa. In a study where DSR was applied with only anterior flaps, the patients were divided into two groups; in the first group, large anterior flaps were created and sutured without creating any posterior flaps, in the second group, after anterior and posterior flaps were created, the posterior flaps were excised and the anterior flaps were combined [10].

While a success rate of $90 \%$ was observed in the first group, this rate was $85 \%$ in the second group [11]. Baldeschi et al. [12] stated that the adhesions formed by the anterior flaps in the deep tissues are one of the most common reasons for the failure of the surgery, to prevent adhesions after creating and combining large 
and free flaps in the nasal mucosa and lacrimal sac, they sutured the flaps to the orbicular muscle in order to remove the flaps from the deep tissues and to increase the opening of the canal. They applied this new technique they reported on 45 patients and reported a $100 \%$ success rate.In another study where they investigated the effect of the lengths of the nonmilked mucosa margins on the success of external DCR and compared three different methods; in the first group, they made only a vertical incision on the pouch while creating a single large anterior flap in the nasal mucosa and sutured the posterior and anterior edges separately,in the second group, they created anterior and posterior flaps in the nasal mucosa and sac and sutured them separately, in the third group, while creating as large anterior flaps as possible in the sac and nasal mucosa, they did not form the posterior flaps and only left the posterior edges while suturing the anterior flaps. Baldeschi et al. [13] found no difference in the success of the surgery between the methods they applied by creating flaps of different shapes and sizes. Becker [14] predicted that granulation tissue created by continuous tear flow would prevent obstruction, and reported $90 \%$ success in the external DCR method applied without creating a flap by modifying the Kasper technique on 50 patients.

There is no consensus among oculoplastic surgeons regarding the application of silicon tube with DSR. While some surgeons reported that silicone tube application should only be applied in problematic situations [15]. Some surgeons apply it in all lacrimal drainage system obstructions. Rosen et al. [16] reported a success rate of $91.3 \%$ in 253 patients who applied silicon tube with external DCR, emphasized that the tube was well tolerated postoperatively and that the complications that occur were rare and benign. Sodhi et al. [17] applied external DCR with bicanalicular silicone tube implantation to 25 patients with chronic dacryocystitis and problems with a low chance of success in terms of DCR and reported a 76\% chance of success. Doğan et al. [18] found a success rate of $85.7 \%$ in the retrospective examination of 70 patients who applied bicanalicular silicone tube with the Kinosian method after four years. Köksal et al. [15] reported a success rate of $80.5 \%$ in 61 patients who performed external lacrimal surgery with silicone tube implantation.
We also applied silicone tube implantation to all of our cases in order to benefit from the compression effect of the silicone tube and to increase our chances of success in this surgical technique where we released the posterior flaps. It has also been reported that silicone tube implantation eases the surgery and facilitates post-op follow-up in cases of excessive bleeding during surgery and nasal mucosal tears [15]. Although the modification made in our study facilitated the application of the technique and shortened the operation time, it was found that the success rate was not much different from the classical External DCR (BSTI) methods.Atrophic mucosa due to chronic rhinitis in 4 of the unsuccessful cases, nasolacrimal duct occlusion due to excessive wound healing due to young age in 6 cases were detected.It was observed that the failure rates and reasons were compatible with similar studies in the literature [19, 20].

\section{Limitations}

The application of the technique in a wide age range is one of the limitations of our study, since the wound healing is not similar in different age groups and the possibility of atrophic mucosa is higher as the age progresses.

\section{CONCLUSION}

Despite this, the results of our study; considering its advantages and complications, this method is important in terms of its emergence as an option that enables shortening the operation time and facilitating surgical maneuvers.

\section{Conflict of interest}

The authors disclosed no conflict of interest during the preparation or publication of this manuscript.

\section{Financing}

The authors disclosed that they did not receive any grant during conduction or writing of this study.

\section{REFERENCES}

1. Çoban DT, Beden U, Sönmez B, Erkan D. [Outcomes of exter- 
nal dacryocystorhinostomy and effects of the incision type on cosmetic and functional outcomes]. J Clin Anal Med 2011;2:214. [Article in Turkish]

2. Yang JW, Oh HN. Success rate and complications of endonasal dacryocystorhinostomy with unciformectomy. Graefes Arch Clin Exp Ophthalmol 2012;250:1509-13.

3. Eroğul Ö, Eroğul LE, Doğan M, Polat O, Buyruk A. Comparison of external dacryocystorhinostomy and transcanalicular multidiod laser dacryocystorhinostomy results in patients with acquired nasolacrimal duct obstruction. Acta Medica Alanya 2017;1:67-71.

4. Lee MJ, Khwarg SI, Kim IH, Choi JH, Choi Y, Kim N, et al. Surgical outcomes of external dacryocystorhinostomy and risk factors for functional failure: a 10-year experience. Eye (Lond.) 2017;31:691-7.

5. El Sawy AM, Hamdi MM, Elwan SS, Abdalla TM. Study of the effect of different designs of nasal mucosal and lacrimal sac flaps on the success rate of external dacryocystorhinostomy. J Egypt Ophthalmol Soc 2017;110:14-21.

6. Katuwal S, Aujla JS, Limbu B, Saiju R, Ruit S. External dacryocystorhinostomy: do we really need to repair the posterior flap? Orbit 2013;32:102-6.

7. Sharma HR, Sharma AK, Sharma R. Modified external dacryocystorhinostomy in primary acquired nasolacrimal duct obstruction. J Clin Diagn Res 2015;9:NC01-5.

8. Leong SC, MacEwen CJ, White PS. A systematic review of outcomes after dacryocystorhinostomy in adults. Am J Rhinol Allergy 2010;24:81-90.

9. Karakurt A, Sarıcaoğlu MS, Baysan A, Bulut AK, Kaçarlar IY, Duru Z, et al. [Surgical success in single flap external dacryocystorhinostomy]. Turkiye Klinikleri J Ophthalmol 2016;25:42-5. [Article in Turkish]

10. Kazancı B, Erşan İ, Özek D, Gencer B. [External dacryocys- torhinostomy: single flap or double flaps anastomosis]. Dicle Med J 2013;40:601-4. [Article in Turkish]

11. Elwan S. A randomized study comparing DCR with and without excision of the posterior mucosal flap. Orbit 2003;22:7-13. 12. Baldeschi L, Nardi M, Hintschich CR, Koornneef L. Anterior suspended flaps: a modified approach for external dacryocystorhinostomy. Br J Ophthalmol 1998;82:790-2.

13. Baldeschi L, MacAndie K, Hintschich CR. The length of unsutured mucosal margins in external dacryocystorhinostomy. Am J Ophthalmol 2004;138:840-4.

14. Becker BB. Dacryocystorhinostomy without flaps. Ophthalmic Surg 1988;19:419-27.

15. Köksal M, Ünal M. Eksternal lakrimal cerrahide silikon tüp endikasyonları. MN Oftalmoloji 1999, 2:151-5.

16. Rosen N, Shark M, Moverman DC, Rosner M. Dacryocystorhinostomy with silicone tubes: evaluation of 253 cases. Ophthalmic Surg 1989;20:115-9.

17. Sodhi PK, Pandey RM, Malik KPS. Experience with bicanalicular intubation of the lacrimal drainage apparatus combined with conventional external dacryocystorhinostomy. J CranioMaxillofac Surg 2003;31:187-90.

18. Doğan H, Erkılıç K, Mirza GE. [The evaluation of postoperative results of different dacryocystorhinostomy methods]. Erciyes Med J 1995;17:239-45. [Article in Turkish]

19. Pokharel SM, Chaudhary SK, Chaurasiya BD. Factors affecting the success rate of external dacryocystorhinostomy at BP Koirala Institute of Health Sciences, Dharan, Nepal. Birat J Health Sci 2017;2:196-200.

20. Yazgan S, Çelik T, Koç H, Doğan M. [Effectiveness of transcanalicular diode laser-assisted dacryocystorhinostomy in cases with failure after at least two external dacryocystorhinostomy: two-year results]. Turkiye Klinikleri J Ophthalmol 2017;26:17580. [Article in Turkish] 